\title{
Role of fetal echocardiography in morphologic and functional assessment of fetal heart in diabetic mothers
}

\author{
Mariam Raafat ${ }^{1,2^{*}}$ (D), Sameh Aborizk', Mahmoud Saraya ${ }^{1}$ and Hazem Hamed Soliman ${ }^{1}$
}

\begin{abstract}
Background: Diabetes mellitus (DM) is the commonest medical disorder faced during pregnancy and it includes type I, type II, and gestational diabetes. It may predispose to various complications including fetus malformation, macrosomia, spontaneous abortion, stillbirth, neonatal death, and intrauterine growth retardation. Hypertrophic cardiomyopathy (HCM) is one of the common anomalies depicted with diabetes. Fetal cardiac function analysis might provide important information on the hemodynamic status and cardiac adaptation to different perinatal complications.

Results: The mean septal thickness in the diabetic group was $0.7163 \pm 0.1746 \mathrm{~cm}$ and $0.4989 \pm 0.08068 \mathrm{~cm}$ in the control group. The mean myocardial thickness of the right ventricular free wall in the diabetic group was $0.6532 \pm$ $0.13792 \mathrm{~cm}$ and $0.4874 \pm 0.07482 \mathrm{~cm}$ in the control group. The mean myocardial thickness of the left ventricular free wall in the diabetic group was $0.6437 \pm 0.13421 \mathrm{~cm}$ and $0.4737 \pm 0.07573 \mathrm{~cm}$ in the control group. The mean value of myocardial performance index (Tie Index) in the diabetic group was $0.6232 \pm 0.15606$ and $0.4626 \pm 0.04357$ in the control group.

Conclusion: From our study, we can conclude that prenatal complete echocardiographic study should be mandatory in fetuses of diabetic mothers due to high risk of congenital heart defects and onset of hypertrophic cardiomyopathy with fetal cardiac function impairment in the third trimester.

Early diagnosis of congenital heart defects as well as evidence of hypertrophic cardiomyopathy and fetal cardiac function impairment that occurs in fetuses of maternal diabetes will definitely guide prompt postnatal therapy and care for those neonates.
\end{abstract}

Keywords: Gestational diabetes, Fetal echocardiogram, Septal thickness, Tie index

\section{Background}

Diabetes mellitus is the commonest medical disorder faced during pregnancy and it includes type I, type II, and gestational diabetes. It may predispose to various complications including fetus malformation, macrosomia, spontaneous abortion, stillbirth, neonatal death, and intrauterine growth retardation [1]. Risk of congenital

\footnotetext{
* Correspondence: mariam_raafat@yahoo.com

'Radiology Department (Women's Imaging Unit), Kasr ElAiny Hospital, Cairo University, Cairo, Egypt

${ }^{2}$ Diagnostic and Intervention Radiology Department, Cairo University Hospitals, Kasr Al-Ainy, El-Manial, Cairo 11956, Egypt
}

anomalies is increased in diabetic mothers' infants with estimation to be between $2.5 \%$ and $12 \%$ with over representation of congenital heart defects [2].

Hypertrophic cardiomyopathy ( $\mathrm{HCM})$ is one of the common congenital anomalies depicted with diabetes mellitus (DM), thus requires high index of suspicion as the specific management may vary; for example, inotropic agents or digoxin which may be used in heart failure associated with structural heart defects are contraindicated if hypertrophic cardiomyopathy is present [3]. The ventricular interventricular septum is preferentially affected, but both right and left ventricular free walls may also be involved, predominantly

\section{Springer Open}

(c) The Author(s). 2020 Open Access This article is licensed under a Creative Commons Attribution 4.0 International License, which permits use, sharing, adaptation, distribution and reproduction in any medium or format, as long as you give appropriate credit to the original author(s) and the source, provide a link to the Creative Commons licence, and indicate if changes were made. The images or other third party material in this article are included in the article's Creative Commons licence, unless indicated otherwise in a credit line to the material. If material is not included in the article's Creative Commons licence and your intended use is not permitted by statutory regulation or exceeds the permitted use, you will need to obtain permission directly from the copyright holder. To view a copy of this licence, visit http://creativecommons.org/licenses/by/4.0/. 
the left. Manifestations of myocardial hypertrophy are often subtle; however, the hypertrophy can be detected by standard fetal echocardiography, usually by comparing septal thickness with control cases [4].

In diabetic mothers' infants, it is suggested that HCM arise from the effects of excess in insulin level. However the mechanisms by which insulin causes ventricular hypertrophy has not yet been explained, but the heart is a main target for insulin, and expression of functional insulin receptors by the cardiomyocyte is comparable with that of other insulin sensitive cells [5]. Thus, it is suggested that increase in fetal insulin level can trigger hyperplasia and hypertrophy of myocardial cells. This hypertrophy mainly affects the interventricular septum and can occur despite tight glycemic control [6].

Gestational diabetes mellitus (GDM) is defined as carbohydrate intolerance recognized for the first time during pregnancy and usually resolves after delivery. The outcome of gestational diabetes is good especially with controlled blood glucose levels. However, GDM increases the risk of a number of fetal adverse outcomes. Fetuses of diabetic mothers are prone to fetal hyperglycemia and hyperinsulinism secondary to maternal hyperglycemia [7].

Despite the recognition of fetal myocardial hypertrophy, there is still controversy about its effect on global cardiac function [6]. However, there are reported cases of severe perinatal cardiac dysfunction and fetal deaths [8].

Fetal cardiac function analysis may provide an important information on the hemodynamic status and on the cardiovascular adaptation for different perinatal adverse effects [9].

A Doppler-derived index of the right and left ventricular myocardial performance combining systolic and diastolic time intervals was described in the literature by Tei et al. 1995 [10] .The Tei Index (TI) has been described to be a non-invasive, useful, Doppler-derived myocardial performance index that acts as a combined index of global myocardial function. By integrating only time intervals, the index is less dependent on precise imaging or anatomy. Moreover, the TI is independent of both ventricular geometry and heart rate. The TI is defined as the summation of the iso-volumic contraction time (ICT) and the iso-volumic relaxation time (IRT) divided by the ejection time (ET) [11] .

\section{Methods}

The objective of this study is to assess the impact of maternal pre-gestational diabetes whether type I or type II and gestational one on fetal cardiac morphology and function.

This study is approved by our institutional review board.

\section{Patients}

A prospective study included 40 metabolically controlled diabetic pregnant ladies and 60 normal non-diabetic pregnant ones (control group) between 28 and 40 weeks gestation dated by LMP. Full history was collected from all ladies including age, parity, and history of drug intake or any associated medical disorders. Fasting blood sugar analysis results are obtained from all cases to differentiate between diabetic and control cases. Fetal biometry was performed for all cases, including measurements of bi-parietal and occipito-frontal diameters, head circumference, abdominal circumference and femur length. Doppler examination of umbilical, middle cerebral arteries and ductus venosus was also done.

\section{Exclusion criteria}

Cases with any other associated medical disorders were excluded from the study.

Cases of structural abnormalities including different fetal systems apart from fetal heart as well as cases of fetal growth restriction (IUGR) were excluded from our study.

Cases of severe polyhydramnios or multiple gestations were excluded from the study.

\section{Imaging protocol}

A complete standardized fetal echocardiogram was performed for all diabetic pregnant ladies for full structural assessment. The control group underwent just basic and extended basic fetal cardiac examination according to (ISUOG guidelines, 2013) [12].

Measurement of the end diastolic IVS (interventricular septal thickness) and myocardial free walls in lateral sub-costal view in some cases and apical or basal four chamber view in other cases (depending on fetal position at the time of scan) just inferior to atrio-ventricular valves were performed for all cases.

Doppler waveform for the left Mod-MPI (modified myocardial performance index) according to Hernandez et al. (2012) [9] was performed. The pulsed Doppler sample volume was placed on inner wall of the ventricular septum above the mitral valve and below the aortic valve in the four chamber view with a basal or an apical projection allowing simultaneous inflow and outflow display from the left ventricle. Then, time periods for the left Mod-MPI were measured:

ICT was measured from the mitral valve closure click to the opening of the aortic valve click.

IRT was measured from the aortic valve closure click to the opening of the mitral valve click.

ET was measured from the opening to the closure of the aortic valve click. 


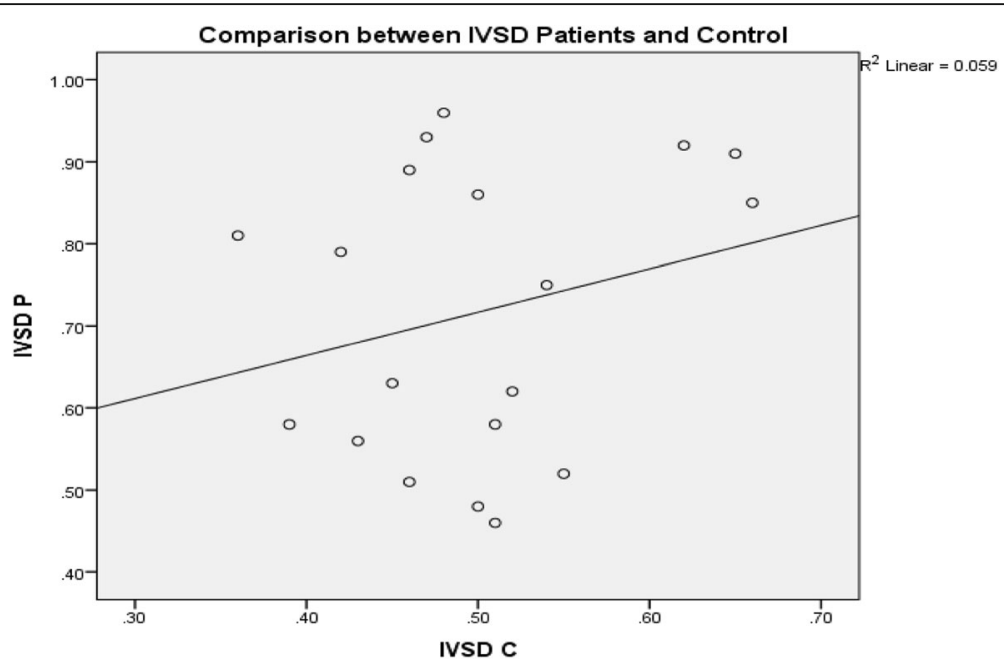

Fig. 1 Linear regression curve to illustrate significant correlation between IVST for both patients and controls (correlation coefficient $R^{2}=0.244$ )

\section{Statistical analysis}

The statistical analysis was carried out using SPSS software package version 17.0 (SPSS Inc., Chicago, IL, USA). Obstetric characteristics were presented as mean + standard deviation. The Tie Index, RV wall thickness, LV wall thickness and IVS thickness obtained from the fetuses were plotted against gestational age and the correlation coefficients were determined by using Pearson's correlation. The normal values of these variables were presented as 5th, 50th, and 95th percentile ranks. $P$ value $<0.05$ was considered statistically significant. Normograms and percentile fitted curves were obtained.

\section{Results}

From 40 diabetic cases examined in our study, 38 was applicable to our study regarding functional assessment using tie index and assessment of septal and myocardial free wall hypertrophy. One of our cases appeared to have a structural heart defect known as visceral heterotaxy syndrome (left isomerism) and the other was diagnosed to have tetralogy of Fallot.

From our statistical results, we found the following:

We found that the mean interventricular septal thickness (IVST) in the diabetics patients group was $0.7163 \pm$ $0.1746 \mathrm{~cm}$ and $0.4989 \pm 0.08068 \mathrm{~cm}$ in the control group (Fig. 1). A significant statistical difference was found regarding the septal thickness between diabetics group and normal group $(P<0.05)$.

We found that the mean myocardial thickness of the right ventricular free wall (RVWT) in the diabetic group was $0.6532 \pm 0.13792 \mathrm{~cm}$ and $0.4874 \pm 0.07482 \mathrm{~cm}$ in the control group (Fig. 2). A significant statistical

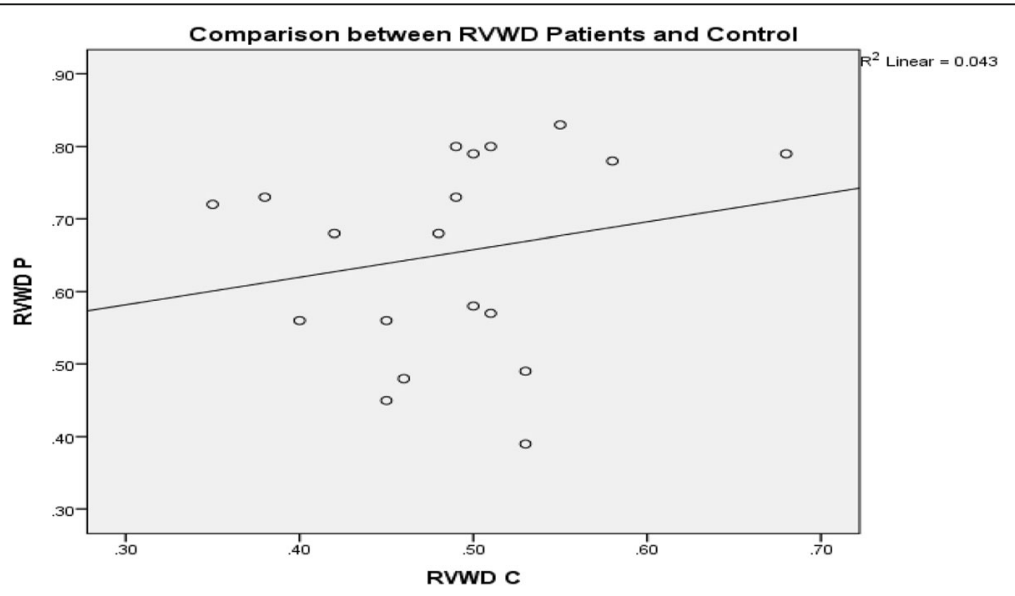

Fig. 2 Linear regression curve to illustrate significant correlation between RWWT for both patients and controls (correlation coefficient $R^{2}=0.206$ ) 


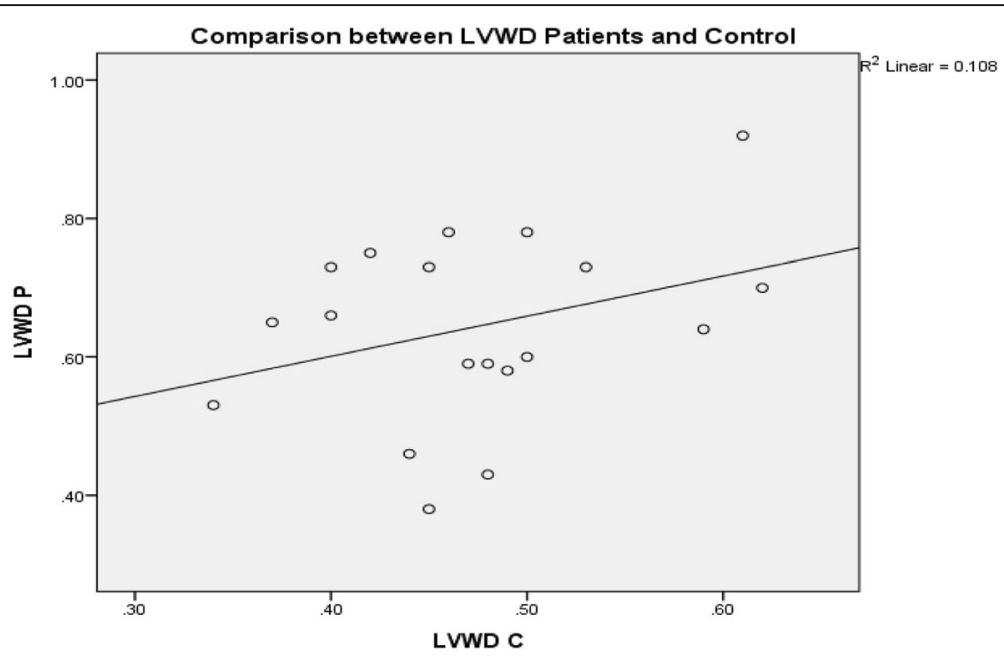

Fig. 3 Linear regression curve to illustrate significant correlation between LWWT for both patients and controls (correlation coefficient $R^{2}=0.32$ )

difference was found regarding the right ventricular free wall myocardial thickness between diabetic group and control group $(P<0.05)$.

We found that the mean myocardial thickness of the left ventricular free wall (LVWT) in the diabetics group was $0.6437 \pm 0.13421 \mathrm{~cm}$ and $0.4737 \pm 0.07573 \mathrm{~cm}$ in the control group (Fig. 3). A significant statistical difference was found regarding the left ventricular free wall myocardial thickness between diabetics group and control group $(P<0.05)$.

We found that the mean myocardial performance index (Tei Index) value in the diabetics group was $0.6232 \pm 0.15606$ and $0.4626 \pm 0.04357$ in the control group (Fig. 4). A significant statistical difference was found regarding the myocardial performance index between diabetic group and control group $(P<0.05)$.
The estimated fetal weight and feto-placental Doppler study did not significantly differ between the diabetics and the control groups.

\section{Discussion}

We aimed in our study to assess the effect of maternal pre-gestational and gestational diabetes on fetal cardiac morphology and function for which complete fetal echocardiogram was performed in every case to rule out any structural defects. Measurement of ventricular myocardial free walls and interventricular septal thickness was done as a tool for evaluation of cardiac hypertrophic cardiomyopathy that occurs in fetuses and neonates of diabetic mothers. Dopplerderived modified myocardial performance index (Mod-MPI) was used to assess global overall systolic

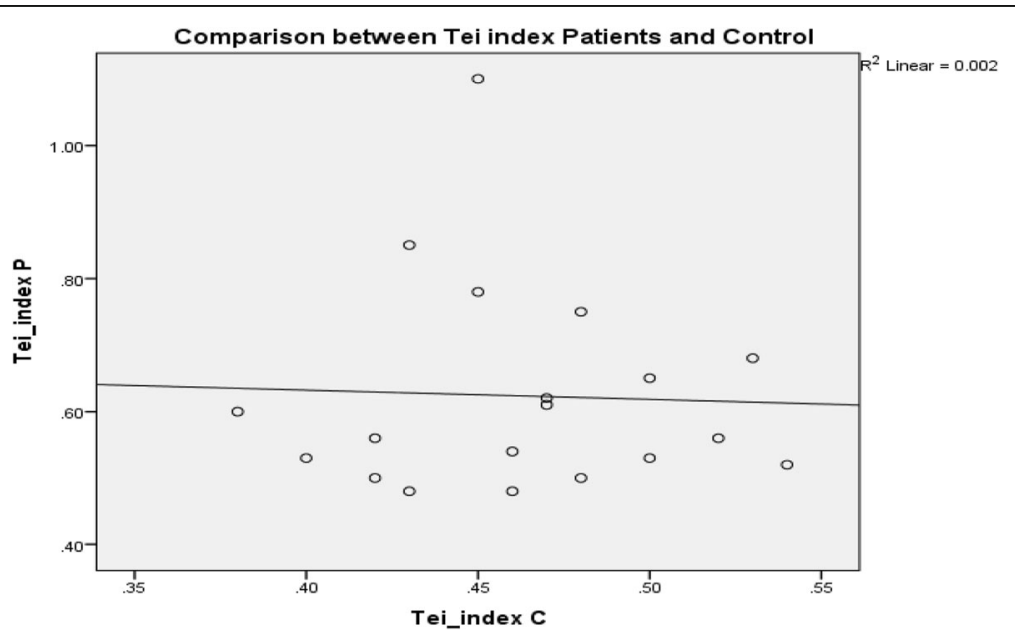

Fig. 4 Linear regression curve to illustrate significant correlation between Tie Index for both patients and controls (correlation coefficient $R^{2}$ $=0.039$ ) 

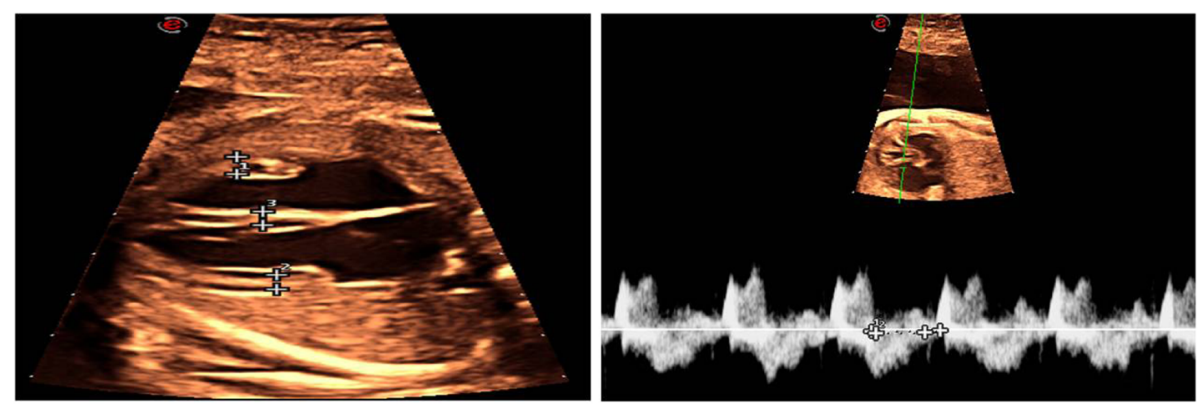

Fig. $52 \mathrm{D}$ measurement of myocardial and septal wall thickness in lateral 4 chamber view and Doppler derived measurement of left modified myocardial performance index in a pregnant female 22 years with no history of maternal diabetes. Both tie index and myocardial and septal wall thickness were within normal ranges $(\mathrm{RWWT}=0.41, \mathrm{LVWT}=0.34$, IVST $=0.32$, Tie $=0.4$ )

and diastolic function to display whether impairment of fetal cardiac function occurred or not.

The study included 40 diabetic pregnant women and 60 control cases. Both groups were within a comparable gestational age (between 28 and 40 weeks gestation).

The mean septal thickness in the diabetics group was $0.7163 \pm 0.17 \mathrm{~cm}$ (Figs. 6 and 7) and $0.4989 \pm 0.08 \mathrm{~cm}$ (Fig. 5) in the normal group.

A significant difference was found regarding the septal thickness between diabetic group and normal group $(P<$ $0.05)$. These results are in concordance with results of previous studies.

Joana et al. (2018) [13] demonstrated that fetuses of diabetic mothers had a significantly thicker interventricular septum compared with control subjects (median, $4.25 \mathrm{~mm}$ [interquartile range (IQR), $3.87-4.50 \mathrm{~mm}$ ] vs $3.67 \mathrm{~mm}$ [IQR, 3.40-3.93 mm), $P<.001$ )

Garcia-Flores et al. (2011) [6] reported that the septal thickness was increased in fetuses of diabetic mothers compared with the control group with statistical significant difference $(P<0.001)$ despite being comparative study between cases of controlled gestational diabetes (cases of increased HbA1c values above $6.5 \%$ were excluded) and normal ones. It was found that $66.6 \%(16 /$
24) of the diabetic pregnancies were above the 95th percentile for the IVS thickness in the control group, which was estimated at $3.51 \mathrm{~mm}$; however, measurements of IVS thickness in both groups were in normal ranges in this study.

Prefumo et al. (2005) [8] reported cases of marked fetal myocardial hypertrophy associated with signs of myocardial insufficiency in fetuses of diabetic mothers.

Balli et al. (2014) [14] showed that the mean septal thickness at 36 weeks gestation was $0.452 \pm 0.49 \mathrm{~cm}$ in group of maternal diabetes compared to $0.38 \pm 1.77 \mathrm{~cm}$ in the control group with a significant statistical difference $(P<0.001)$. In this study, despite being statistically different, no pathological IVS hypertrophy was found. However, evidence of diastolic dysfunction in the study group was found by application of different parameters for assessing diastolic dysfunction.

This study has shown that maternal diabetes was associated with a significantly increased thickness of all cardiac walls (Figs. 6 and 7) compared with normal pregnancies (Fig. 5), confirming in part the results of previous studies done by Jaeggi et al. 2001 [15]. Penney et al. (2003) [16] focused on cases with pre-existing diabetes, but Zielinsky, 2009 [17] applied his study on
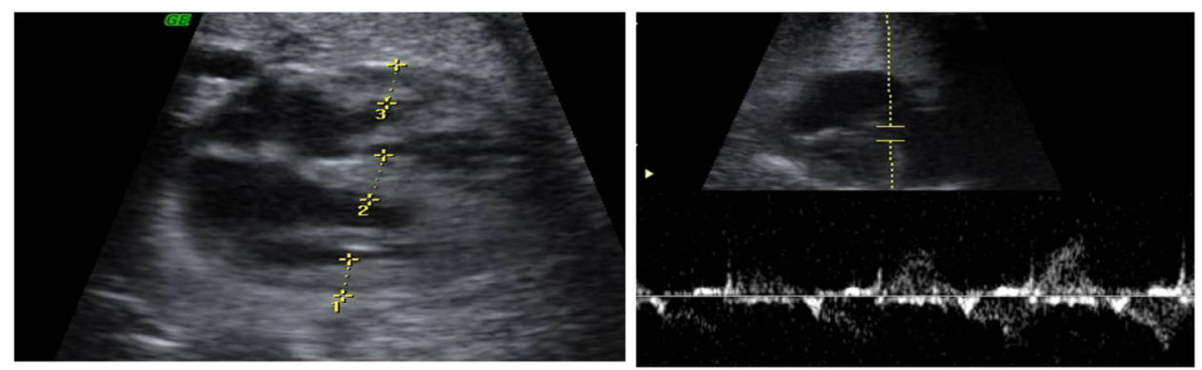

Fig. $62 \mathrm{D}$ measurement of myocardial and septal wall thickness in lateral 4 chamber view and Doppler derived measurement of left modified myocardial performance index in a pregnant female 25 years, with history of type I diabetes on regular insulin therapy came for routine antenatal ultrasound at 30 weeks gestation. Abnormal increase in myocardial and septal wall thickness with abnormally high MPA above the reference values $(\mathrm{RVWT}=0.81, \mathrm{LWWT}=0.86$, IVST $=1$, Tie $=0.67$ ) 

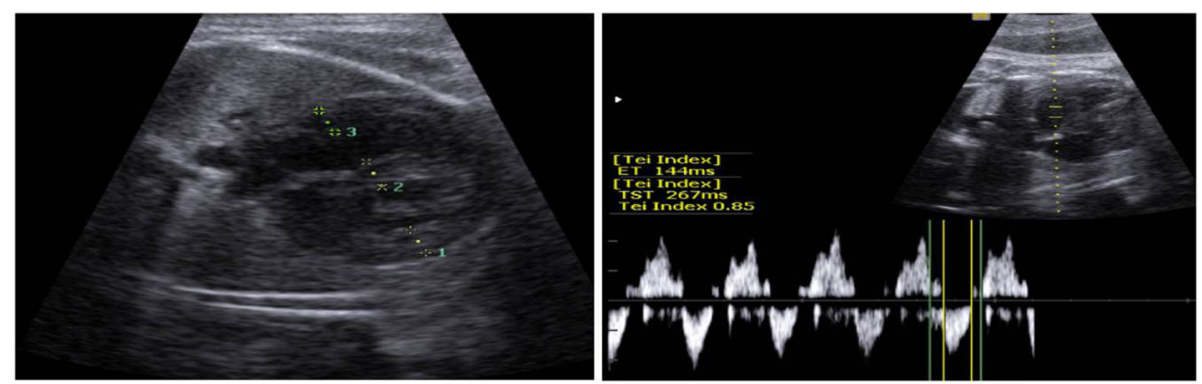

Fig. $72 \mathrm{D}$ measurement of myocardial and septal wall thickness in lateral 4 chamber view and Doppler derived measurement of left modified myocardial performance index in a pregnant female 32 years, with history of type II diabetes on regular oral hypoglycemic therapy came for routine antenatal ultrasound at 29 weeks gestation. AAbnormal increase in myocardial and septal wall thickness with abnormally high MPA above the reference values (RVWT $=0.68, \mathrm{LVWT}=0.65, \mathrm{IVST}=0.75$, Tie $=0.85$ )

population with gestational diabetes mellitus. Both of them reported significant difference in myocardial-free walls and interventricular septal thickness between both studies and control groups.

In a series of neonates and infants, the cardiomyopathy (CM) was noticed in about $2-7 \%$, but probably during the fetal life the prevalence is higher reaching $6-11 \%$. The high intrauterine loss, occurring in almost one third of affected fetuses, most likely explains these differences [18].

Still, authors can find some cases with septal hypertrophy, which are not symptomatic postnatally. Although most symptoms of cardiomyopathy may spontaneously regress within few weeks, sometimes, overt congestive heart failure develops, tachycardia, tachypnea, gallop rhythm, and hepatomegaly [19].

In our study, the mean septal and myocardial free wall thickness was statistically significant compared to the control group with above $95^{\text {th }}$ percentile mean value of tie index denoting evidence of hypertrophic cardiomyopathy with impairment of left ventricular function.

It was not possible in this study, to expect, whether theses fetuses would be symptomatic or not by the ultrasound and Doppler criteria. Postnatal evaluation by a specialized neonatologist and a cardiologist is recommended.

Some studies suggest that gestational diabetes can be a risk factor for congenital heart defects, but there are still controversies about the extent of such association [20].

In our study, the incidence of congenital heart defects among study cases represents $5 \%$ of the total number of cases with diabetes. Previous studies showed an $8.5 \%$ incidence of cardiac malformations in fetuses of diabetic pregnancies [21]. Our study was restricted to the limited patients' number involved in our study; however, if a large number of diabetic patients could be included, incidence might become different.

In our study, we also aimed to assess the effect of maternal diabetes on fetal myocardial function using the Modified myocardial performance index (MPI).
MPI is a global indicator of cardiac function. Increased in MPI indicates globally impaired ventricular function in maternal diabetes during the intermediate and late pregnancy periods [22]. Hernandez-Andrade et al.(2012) [9] defined age-adjusted reference values for the left ventricular Mod-MPI in normal fetuses at 19-39 weeks gestation and calculated the 5th, 50th, and 95th percentiles for the Mod-MPI as well as its components (ICT, ET, and IRT). It was found that in normal fetuses, the ModMPI did not exceed 0.43 at any gestation (at a fetal heart rate of $140 \mathrm{bpm}$ : median 0.45 range $0.36-0.54$ ). Another more recent study revealed the normal value of MPI is about $0.51 \pm 0.12$ [23]. These values are in close agreement with our results for the control group, but are much lower than those in the study group indicating reduced left ventricular wall compliance in fetuses of diabetic mothers with subsequent impairment of fetal overall cardiac function.

Our study showed a statistically significant $(P<0.001)$ higher overall Mod-MPI in the study group as a whole (median 0.61, range 0.39-0.83) compared to the control group (median 0.47, range 0.32-0.62).

\section{Conclusion}

From our study, we can conclude that prenatal complete echocardiographic study should be mandatory due to high risk of congenital heart defects and onset of hypertrophic cardiomyopathy with impairment of fetal cardiac function in fetuses of diabetic mothers in the third trimester.

Early diagnosis of congenital heart defects, impairment of fetal cardiac function as well as evidence of hypertrophic cardiomyopathy that occurs in fetuses of maternal diabetes will definitely guide prompt postnatal therapy and care for those neonates.

\section{Abbreviations}

HCM: Hypertophic cardiomyopathy; GDM: Gestational diabetes mellitus;

TI: Tie Index; IUGR: Intra uterine growth restriction; ICT: Isovolumic 
contraction time; IRT: Isovolumic relaxation time; ET: Ejection time; IVS: Interventricular septum; MOD-MPI: Modified myocardial index; RWWT: Right ventricular wall thickness; LWWT: Left ventricular wall thickness; IQR: Interquartile range

\section{Acknowledgements}

No acknowledgements

\section{Authors' contributions}

MR contributed in the study conception and design, collected patients' data, wrote, and edited the manuscript. SA helped in collecting and interpretation of data. MS contributed in referral and follow-up of the cases. HS helped in the study design and statistical analysis. All authors read and approved the final manuscript.

\section{Funding}

No funding sources

\section{Availability of data and materials}

Available with the corresponding author upon request.

\section{Ethics approval and consent to participate}

Written informed consent was signed by all patients before examination. The study was approved by the ethics committee of faculty of medicine, Cairo University. Reference number is not applicable.

\section{Consent for publication}

All patients included in this research are above 16 years and all gave written informed consent to publish the data contained within this study.

\section{Competing interests}

The authors declare that they have no competing interests.

Received: 21 October 2019 Accepted: 18 May 2020

Published online: 27 May 2020

\section{References}

1. Temple R (2006) Diabetes in pregnancy. Medicine 34(3):111-112

2. Hornberger LK (2006) Maternal diabetes and the fetal heart. Heart 92:10191021

3. Russell NE, Holloway P, Quinn S, Foley M, Kelehan P, McAuliffe FM (2007) Cardiomyopathy and cardiomegaly in stillborn infants of diabetic mothers. Pediatr Dev Pathol 11(1):10-14

4. Zielinsky P, Piccoli AL (2012) Myocardial hypertrophy and dysfunction in maternal diabetes. Early Hum Dev 88(5):273-278

5. Huang T, Kelly A, Becker SA, Cohen MS, Stanley CA (2013) Hypertrophic cardiomyopathy in neonates with congenital hyperinsulinism. Arch Dis Child Fetal Neonatal Ed 98(4):F351-F354

6. Garcia-Flores J, Jañez M, Gonzalez MC, Martinez N, Espada M, Gonzalez A (2011) Fetal myocardial morphological and functional changes associated with well-controlled gestational diabetes. Eur J Obstet Gynecol Reprod Biol 154:24-26

7. Mehta A, Hussain K (2003) Transient hyperinsulinism associated with macrosomia, hypertrophic obstructive cardiomyopathy, hepatomegaly, and nephromegaly. Arch Dis Child 88(9):822-824

8. Prefumo F, Celentano C, Presti F, De Biasio P, Venturini PL. Acute presentation of fetal hypertrophic cardiomyopathy in a type 1 diabetic pregnancy. Diabetes Care 2005;28(August (8)):2084

9. Hernandez Andrade E, Benavides JA, Serralde Cruz R, Martinez Welsh A Mancilla Ramirez J (2012) Evaluation of conventional Doppler fetal cardiac function parameters: E/A ratios, outflow tracts, and myocardial performance index. Fetal Diagn Ther 32:22-29

10. Tei C, Lieng H, David O, Kent R, Jae K, Richard J, Jamil A, James B (1995) New index of combined systolic and diastolic myocardial performance :A simple and reproducible measure of cardiac function-A study in normal and dilated cardiomyopathy. J Cardiology:26, 357-366

11. Freedom RM, Jaeggi ET, Lim JS, Anderson RH (2005) Hearts with isomerism of the right atrial appendages-one of the worst forms of disease in 2005. Cardiol Young 15(06):554-567

12. Caravelho JS, Allan LD, Chaoui R, Copel JA, Devore GR, Hecher K, Lee W (2013) International Society of Ultrasound in Obstetrics and Gynecology.
Practice guidelines (updated) : sonongraphic screening examination of the fetal heart. Ultrasound Obstet Gynecol ; volume 41, issue 3.

13. Miranda JO, Cerqueira RJ, Ramalho C, Areias JC, Henriques-Coelho T (2018) A Conventional and Speckle-Tracking Echocardiographic Study. Journal of the American Society of Echocardiography 31(3):333-341

14. Balli S, Pac FA, Ece I, Oflaz MB, Kibar AE, KandemirÖ (2014) Assessment of cardiac functions in fetuses of gestational diabetic mothers. Pediatr Cardiol 35(1):30-37

15. Jaeggi ET, Fouron JC, Proulx F (2001) Fetal cardiac performance in uncomplicated and well-controlled maternal type I diabetes. Ultrasound Obstet Gynecol 17(4):311-315

16. Penney GC, Mair G, Pearson DW (2003) Outcomes of pregnancies in women with type 1 diabetes in Scotland: a national population-based study. BJOG 110(3):315-318

17. Zielinsky P, Piccoli Jr A, Manica JL, Nicoloso LH. (2009): Diseases of the myocardium, endocardium and pericardium during fetal life. In : Yagel S, Silverman N, Cohen SM(eds). Fetal Cardiology: Embryology, Genetics, Physiology, Echocardio- graphic evaluation, Diagnosis and Perinatal Management of Cardiac Disease. 2nd ed. New York: Informa Healthcare; P: 366

18. Mongiovì M, Fesslova V, Fazio G, Barbaro G, Pipitone S (2013) Diagnosis and prognosis of fetal cardiomyopathies: a review. Curr Pharm Des 16(26):2929-2934

19. Stuart A, Amer-Wåhlin I, Persson J, Källen K (2013) Long-term cardiovascular risk in relation to birth weight and exposure to maternal diabetes mellitus. Int J Cardiol 168(3):2653-2657

20. Botto LD, Goldmuntz E, Lin AE (2008) In: Hugh A, Driscoll D, Shaddy R. (eds). Moss and Adams' heart disease in infants, children, and adolescents: including the fetus and young Adult.7th ed. Philadelphia: Lippincott Williams \& Wilkins.; P: 535.

21. Lisowski LA, Verheijen PM, Copel JA, Kleinman CS, Wassink S, Visser GH, Meijboom EJ (2010) Congenital heart disease in pregnancies complicated by maternal diabetes mellitus. An international clinical collaboration, literature review, and metaanalysis. Herz;35(1):19-26.

22. Api O, Emeksiz MB, Api M, Ugurel V, Unal O (2009) Modified myocardial performance index for evaluation of fetal cardiac function in pre-eclampsia. Ultrasound Obstet Gynecol 33:51-57

23. Luliu C, Mihailescu, Mitran M, Marinescu B (2014): The role of myocardial performance index (tie index) in exploring fetal cardiac function, Gineco.eu J Obstetrics and Gynecology Vol. 10 Nr. 36 (2/2014).

\section{Publisher's Note}

Springer Nature remains neutral with regard to jurisdictional claims in published maps and institutional affiliations.

\section{Submit your manuscript to a SpringerOpen ${ }^{\circ}$ journal and benefit from:}

- Convenient online submission

- Rigorous peer review

- Open access: articles freely available online

High visibility within the field

- Retaining the copyright to your article

Submit your next manuscript at $\boldsymbol{\nabla}$ springeropen.com 